\title{
Investigation of the Barrier Effectiveness in Open-Planned Offices: A Sample Analysis
}

\author{
Zuhal Ozcetin \\ Faculty of Fine Arts and Design, Department of Architecture, \\ Siirt University, Siirt, Turkey \\ E-mail: zuhalozcetin@gmail.com \\ Merve Gorkem \\ MEGO Dan. Mim. Muh. Ins. San. ve Tic. Ltd. Sti. \\ Ankara, Turkey \\ E-mail: mervedogangorkem@gmail.com \\ Fusun Demirel \\ Faculty of Architecture, Department of Architecture, \\ Gazi University, Ankara, Turkey \\ E-mail: fusund@gazi.edu.tr
}

\begin{abstract}
It is possible to give speech sound as the primary source of noise in open plan offices. The noise caused by the speech voice has an impact on both the intelligibility of speech and the confidentiality of speech. For jobs and areas that require a high level of perception, the acoustically unsuitable work environment often causes distraction, resulting in a reduction in labor productivity. Therefore, in the study: it is aimed to present concrete precautions to be taken in order to provide auditory comfort for open plan offices at the design stage. According to TS EN ISO 3382-3 standard, STI value in the nearest working unit, Aweighted sound pressure level of the speech unit, as well as distance $(\mathrm{rD})$ and distance $(\mathrm{rP})$ where privacy begins to decrease over two open-plan office projects. The relationship between the rate of reduction (D2, S), the A-weighted sound pressure level (Lp, A, S, 4 m) of the speech sound at a distance of 4m, the background noise level (Lp, A, B) with the variability of the obstacle design used between ODEON 15.14 volume acoustics were analyzed and analyzed by simulation program.
\end{abstract}

Keywords: Open-planned office, barrier design, architectural acoustics, noise control.

DOI: $10.7176 /$ JSTR/6-04-10

\section{Açık Planlı Ofislerde Engel Etkinliğinin Örnekler Üzerinden İncelenmesi}

Özet

Açık planlı ofislerde birincil gürültü kaynağ 1 olarak konuşma sesini vermek mümkündür. Konuşma sesinin neden olduğu gürültü, hem konuşmanın anlaşılabilirliği, hem de konuşmanın gizliliği üzerinde oldukça etkilidir. Yüksek algı seviyesi isteyen işler ve alanlar için, çalışma ortamının akustik açıdan uygun olmaması, çoğu zaman dikkat dağınıklığına, bunun sonucu işgücü verimliliğinde azalmaya neden olmaktadır. Bundan dolayı çalışmada: tasarım aşamasında açık planlı ofisler için, işitsel konforun sağlanmasına yönelik alınması gereken önlemlerin somut olarak ortaya konulması amaçlanmıştır. TS EN ISO 3382-3 standardına göre, iki açık planlı ofis projesi üzerinden, dikkat dağınıklığının azalmaya başladığı uzaklık (rD) ve gizliliğin başladığı uzaklık (rP) parametrelerinin yanı sıra, en yakın çalışma birimindeki STI değeri, konuşma sesinin A-ağırlıklı ses basınç düzeyinin azalma oranı (D2,S), 4m uzaklıktaki konuşma sesinin A ağırlıklı ses basınç düzeyi (Lp,A,S,4 m), arka plan gürültü düzeyi (Lp,A,B) parametrelerinin çalışma birimleri arasında kullanılan engel tasarımının değişkenliği ile ilişkisi ODEON 15.14 hacim akustiği simülasyon programı ile analiz edilerek değerlendirilmiştir.

Anahtar Kelimeler: Açık planlı ofis, engel tasarımı, mimari akustik, gürültü kontrolü. 


\section{Giriş}

Günümüzde büyük şehirlerde nüfusun büyük bir bölümü zamanını ofislerde geçirmektedir. İnsanların beynini ve fiziksel gücünü en çok kullandıkları hacimlerden biri ofis mekânlarıdır. Bu nedenle ofislerin gürülttüye duyarlı hacimler ile gürültü kaynaklarını ve gürültü kaynağı olan hacimleri bir arada barındırdığı bir gerçektir. Ayrıca bu tür mekânlarda bölme elemanlar bulunmadığından, brüt tavan tasarımının yaygın kullanılmasından dolayı konuşma, telefon ve diğer ofis araç gereçlerinden kaynaklanan sesler çalışma verimini düşürmektedir. Bundan dolayı, açık planlı ofisler gürültü denetiminin yapılmasi gereken zorunlu hacimlerdir.

Üretken olan insanların, ofis mekanlarında, eylem sürecine uygun ortamlarda çalışması gerekmektedir. Bu tür ortamlar "fizik ortam" olarak isimlendirilir. Fizik ortam ögelerinden ışık, ses-gürültü, 1sı, renk, güneş ışınımları gibi faktörlerin ofis binalarının projelendirilme aşamasında düşünülmesi ve iyi etüt edilmesi gerekmektedir. Çağdaş mimarlığa baktığımızda, insanların farklı eylemler için en uygun fiziksel ortam koşullarının sağlanmasını ve mimariyle bütünlüğünü sağlanma amacındadır.

Açık ofislerde mahremiyet, öncelikli ve gereksinim duyulan bir davranış biçimidir. Çalışma ortamında özellikle işitsel ve görsel mahremiyet çok önemlidir [1]. Ofis çalışanları, genellikle rahatsız edici gürülttünün, iş verimini olumsuz etkilediğini düşünürler. Aşırı gürültüu, çalışanların stres seviyesini artırır, konsantrasyonda, iş performansında ve iş konforunda azalmaya sebep olur. Bu bağlamda kabul edilebilir gürültü seviyesini oluşturmak açık ofislerin önceliklerinden biri olmaktadır [2].

Açık planlı ofislerde konuşma sesi, birincil gürülttü kaynağıdır. Konuşma sesinin neden olduğu rahatsılık hem konuşmanın anlaşılabilirliği hem de konuşmanın gizliliği üzerinde etkilere sebep olmaktadır. Özellikle yüksek konsantrasyon gerektiren iş alanları için, çalışma ortamının akustik açıdan uygun olmaması, çoğu zaman dikkat dağınıklığına, dolayısıyla işgücü verimliliğinde azalmaya neden olacaktır.

Açık planlı ofislerde, ister insan ister makine olsun gürültü kaynakları ile alıcıların aynı mekanı paylaşma zorunluluğu akustik konforun sağlanmasını zorlaştırmaktadır. Verimlilik ve açık planlı ofislerin akustik tasarımında ciddi çelişkiler oluşabilmektedir. Akustik konforun sağlanamaması durumunda; dikkatin dağılması, konuşma seviyesinin artması gibi üretkenliği ve verimliliği azaltıcı sonuçlar oluşabilmektedir [1]. Açık planlı ofislerin tasarımında akustik, mekanın kullanım performansını doğrudan etkileyen bir özellik oluşturmaktadır. Akustik konforu sağlayacak koşulların oluşması, tefriş tasarımından asma tavan özelliklerine, mobilya seçiminden bölme elemanlarının boyutuna, hatta aydınlatma aygıtlarının biçimine varıncaya kadar, ofis içerisinde yer alan her nesnenin özenle ele alınıp incelenmesini gerektirir [3]. Açık planlı ofislerde kabul edilebilir gürültü seviyesinin oluşturulmasında en önemli üç önlem [4]; 1. Çalışan kişilerin birbiri ile gereksiz konuşmalar yapmasını engellemek amacıyla aralarına paneller yerleştirmek (1.6 m veya daha uzun).

2. Yutuculuk oranı $\% 90$ ve daha fazla olan özellikte, yüksek tavanlı ofisler tasarlamak.

3. Büro çalışanlarının kendilerine ait çalışma alanlarını geniş tutmaktır.

\section{Yöntem}

Çalışmada, iki farklı ölçekte açık planlı ofis projesi üzerinden, Odeon (v 15.14) bilgisayar simülasyon programı ile, TS EN ISO 3382-3 standardına göre kabul edilen akustik parametreleri incelenmiş, çalışma birimleri arasında kullanılan engel tasarımının değişkenliği ile parametrelerin ilişkisi, analiz edilerek değerlendirilmişsir.

Çalışma kapsamında, açık planlı ofislerin hacmi, oturum düzeni ve malzeme kararları sabit tutularak, sadece çalışma birimleri arasındaki engellerin farklı boyutlarda kullanımı ele alınmıştır. Ofís içerisindeki malzeme kararları; optimum reverberasyon süresini sağlayacak şekilde tavanda ses yutucu kullanılarak tasarlanmıştır.

\section{Açık Planlı Ofisler}

Eğitim binası konferans salonunda karşılaştırması yapılacak olan perfore ahşap panel ve perfore alçı panel kullanımına göre, ayrı ayrı yapılan değerlendirmeler ve kıyaslamalar; reverberasyon süresi $\left(T_{30}\right)$, erken sönümlenme süresi (EDT), konuşmanın iletim indeksi (konuşmanın anlaşılabilirliği) (STI), Aağırlıklı ses basınç seviyesi (SPL(A)), konuşmanın belirginliği $\left(\mathrm{D}_{50}\right)$ parametreleri doğrultusunda yapılmıştır. Salon içerisinde kullanılan malzemelerin ses yutma katsayıları çizelge 1'de verilmiştir.

Genelde ofisleri; bir örgütte ya da kurumda bilgi üretimi ve aktarımını sağlayan işlemler ve bu işlemlerin gerçekleştirilmesini sağlayan insan-makine sistemleri olarak tanımlamak mümkündür [5].

Fakat ofisleri sadece işlevsel anlamda hizmet eden birimler olarak değil, birçok çalışanın günün büyük bir bölümünde zaman geçirdiği yer olarak ele almak, ofislerdeki fiziksel çevreyi özenle tasarlamak ve yönetmek gerekir. Çünkü bu mekânlarda çalışan kişilerin yaşadığ 1 fiziksel şartlar; memnuniyetin, konforun, refahın ve verimliliğin belirleyici faktörleri olarak sayılabilir [6]. Ofis tasarımında uygun 
olmayan tercihler, çalışan kişilerin iş gücünü zayıflatırken, çalışma ortamının konforunu tehlikeye sokabilir ve çalışanların etkin bir şekilde çalışmalarını zorlaştırabilir. Bundan dolayı başta maliyetleri azaltmak için yapılan yanlış tasarım kararları, sonuç olarak daha pahalıya mal olabilir [7].

Kanada Ulusal Araştırma Konseyi (National Research Council Canada (NRCC)'nin 2004 yılında sonuçlandırdığı ofis ortam çalışanlarının memnuniyeti üzerindeki etkisini inceleyen Maliyet Etkin Açık Plan Çevre (COPE) projesi kapsamında yayınlanan doküman, açık plan ofislerin tasarımı ve yönetimine ilişkin aşağıdaki noktalarda dikkat çekmektedir [8].

- Mahremiyet ve akustik

- Kapalı mekândaki hava kalitesi ve ısı konforu

- Işıklandırma ve gün ışı̆̆ından yararlanma durumu

- Çalışma mekânlarının tasarımı ve yerleşimi

\subsection{Açık Planlı Ofislerin Mevcut Durum Analizi}

İncelenen açık planlı ofislerden 1 numaralı ofis (Ofis-1), yaklaşık $200 \mathrm{~m}^{2}$ alana ve $1000 \mathrm{~m}^{3}$ hacme sahip olup, dikdörtgen plan şemasındadır. Plan düzleminde açık ofis alanının uzun iki kenarında özel ofis odaları tasarlanmıştır (Şekil 1). Açık planlı ofislerden 2 numaralı ofis ise (Ofis-2); yaklaşık $680 \mathrm{~m}^{2}$ alana ve $3000 \mathrm{~m}^{3}$ hacme sahip olup, diğer ofis gibi dikdörtgen plan şemasındadır. Plan düzlemi ofis-1 gibi uzun iki kenarında özel ofis odaları yer almaktadır.

Özel ofisler, açık ofis alanından camlı bölmeler ile ayrılmıştır ve odaların yüksekliği 2.50 m'dir. Döşeme kaplaması PVC kaplama olarak karar verilmiştir. Açık ofis alan tavanı brüt tavan olarak tasarlanmıştır. Açık ofis alanlarının tavanı ve özel ofislerin tavanının açık ofis alanına bakan bölümünde optimum reverberasyon süresini sağlayacak şekilde mimari proje tasarımına uygun ses yutucu tasarımı yapılmıştır. Arka plan gürültü düzeyi NC 35 (44 dBA) olarak ele alınmıştır [9].

\section{Açık Planlı Ofislerin Hacim Akustiği Açısından Değerlendirilmesi}

Hacim akustiği açışından mekân içerisindeki akustik konforun değerlendirilmesi analizleri;

- Konuşmanın anlaşılabilirliği (speech intelligibility) ve

- Konuşmanın gizliliğine (speech privacy) yönelik olarak TS EN ISO 3382-3 [10] standardına göre aşağıdaki verilen parametreler doğrultusunda incelenmiştir.

$\begin{array}{ll}\text { STI } & : \text { En yakın çalışma birimindeki STI değeri } \\ & \text { (STI in the nearest workstation) } \\ \mathrm{rD} & : \text { Dikkat dağınıklığının azalmaya başladı̆̆ı uzaklık (STI'daki mekânsal azalma) } \\ & \text { (Distraction distance, in m) } \\ \mathrm{rP} & : \text { Gizliliğin başladığı uzaklık (STI'daki mekânsal azalma) } \\ & \text { (Privacy distance, in m) } \\ \mathrm{D}_{2, \mathrm{~S}} / \mathrm{D}_{\mathrm{L} 2} & : \text { Konuşma sesinin A-ağırlıklı ses basınç düzeyinin azalma oranı } \\ & \text { (mekânsal sönümlenme miktarı) (Spatial decay rate of A-weighted SPL of speech, in } \\ & \mathrm{dB}) \\ \mathrm{L}_{\mathrm{p}, \mathrm{A}, \mathrm{S}, 4 \mathrm{~m}} & : \text { 4m uzaklıktaki konuşma sesinin A ağırlıklı ses basınç düzeyi } \\ & \text { (A-weighted SPL of speech at } 4 \text { metres, in dB) } \\ \mathrm{L}_{\mathrm{p}, \mathrm{A}, \mathrm{B}} & : \text { Arka plan gürültü düzeyi } \\ & \text { (Average A-weighted background noise, in dB) } \\ \mathrm{T}_{30}, \mathrm{~T}_{60} & : \text { Reverberasyon süresi (sn) } \\ & \text { (Reverberation Time) }\end{array}$


Tablo 1. Performans kriterlerine göre analiz sonuçları

\begin{tabular}{|c|c|}
\hline Hacim Akustiği Performans Kriterleri & Optimum Değerler \\
\hline $\begin{array}{l}\text { En yakın çalışma birimindeki STI değeri (STI } \\
\text { in the nearest Workstation) }\end{array}$ & $\begin{array}{l}\text { STI değerinin en yakın çalışma biriminde }<0,50 \\
\text { olmalıdır [10]. }\end{array}$ \\
\hline $\begin{array}{l}\text { Dikkat dağınıklığının azalmaya başladığ } 1 \\
\text { uzaklık }\left(\mathrm{r}_{\mathrm{D}}\right) \text { (STI daki mekânsal azalma) } \\
\left.\text { (Distraction distance, } \mathrm{r}_{\mathrm{D}} \text {, in } \mathrm{m}\right)\end{array}$ & \multirow[t]{2}{*}{$\begin{array}{l}r_{D}>10 m \text { ise kötü bir ofis; eğer } r_{D} \leq 5 \mathrm{~m} \text { ise iyi bir } \\
\text { ofistir [10]. }\end{array}$} \\
\hline $\begin{array}{l}\text { Gizliliğin başladığı uzaklık ( } \mathrm{r}_{\mathrm{P}} \text { ) (STI daki } \\
\text { mekânsal azalma) (Privacy distance, } \mathrm{r}_{\mathrm{P}} \text {, in } \mathrm{m} \text { ) }\end{array}$ & \\
\hline 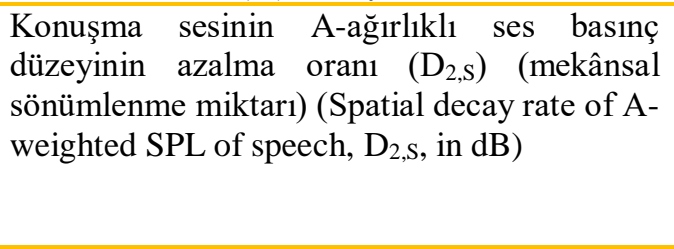 & $\begin{array}{l}\mathrm{D}_{2, \mathrm{~S}}<5 \mathrm{~dB} \text { ise kötü bir ofis, } \mathrm{D}_{2, \mathrm{~S}} \geq 7 \mathrm{~dB} \text { iyi bir } \\
\text { ofistir [10]. DL } \mathrm{DL}_{2}>4 \mathrm{~dB} \text { ise iyi ofistir [11]. Ayrıca } \\
\mathrm{DL}_{2} \text { parametresinin Virjonen ve arkadaşlarının } \\
(2009) \text { yayınladıları makaleye göre } \\
\text { gruplandırılmasına göre ise A sınıfı bir aç1k planlı } \\
\text { ofis için } \mathrm{DL}_{2}>11 \mathrm{~dB}[12,13] \text {. }\end{array}$ \\
\hline $\begin{array}{l}4 \mathrm{~m} \text { uzaklıktaki konuşma sesinin A ağırlıklı ses } \\
\text { basınç düzeyi ( } \mathrm{L}_{\mathrm{p}, \mathrm{A}, \mathrm{S}, 4 \mathrm{~m})} \text { (A-weighted SPL of } \\
\text { speech at } 4 \text { metres, } \mathrm{L}_{\mathrm{p}, \mathrm{A}, \mathrm{S}, 4 \mathrm{~m} \text {, in } \mathrm{dB} \text { ) }}\end{array}$ & $\begin{array}{l}\mathrm{L}_{\mathrm{p}, \mathrm{A}, \mathrm{S}, 4 \mathrm{~m}}>50 \mathrm{~dB} \text { ise kötü bir ofis, } \mathrm{L}_{\mathrm{p}, \mathrm{A}, \mathrm{S}, 4 \mathrm{~m}} \leq 48 \mathrm{~dB} \\
\text { ise iyi bir ofistir [10]. }\end{array}$ \\
\hline $\begin{array}{l}\text { Arka plan gürültü düzeyi }\left(\mathrm{L}_{\mathrm{p}, \mathrm{A}, \mathrm{B}}\right) \text { (Average } \mathrm{A} \text { - } \\
\left.\text { weighted background noise, } \mathrm{L}_{\mathrm{p}, \mathrm{A}, \mathrm{B}} \text {, in } \mathrm{dB}\right)\end{array}$ & $38-48[14]$ \\
\hline
\end{tabular}

\subsubsection{Açık planlı ofis-1 değerlendirilmesi:}

Açık planlı ofis-1 değerlendirilmesinde;

Tavan için;

- Perfore alçı panel asma tavan (taş yünü dolgulu)

- Cam tülü kaplı taş yünü kullanımı önerilmiştir.

- Masalar arası bölmeler için;

- Kumaş kaplı akustik panel kullanımı önerilmiştir (Şekil 1, Şekil 2)

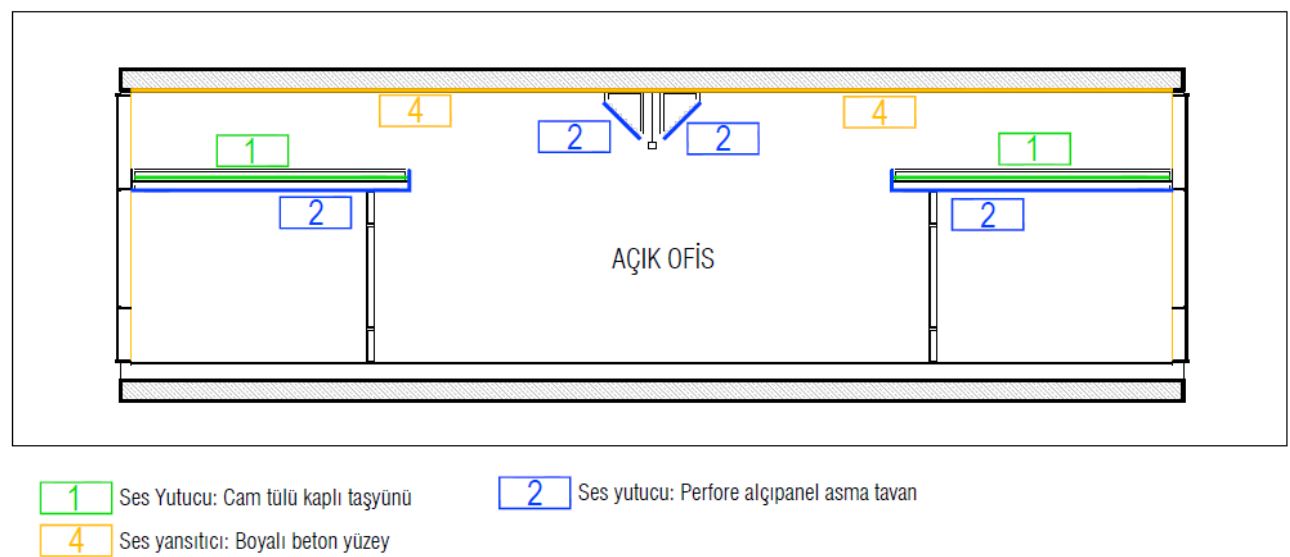

Şekil 1. Açık planlı ofis-1 kesiti 


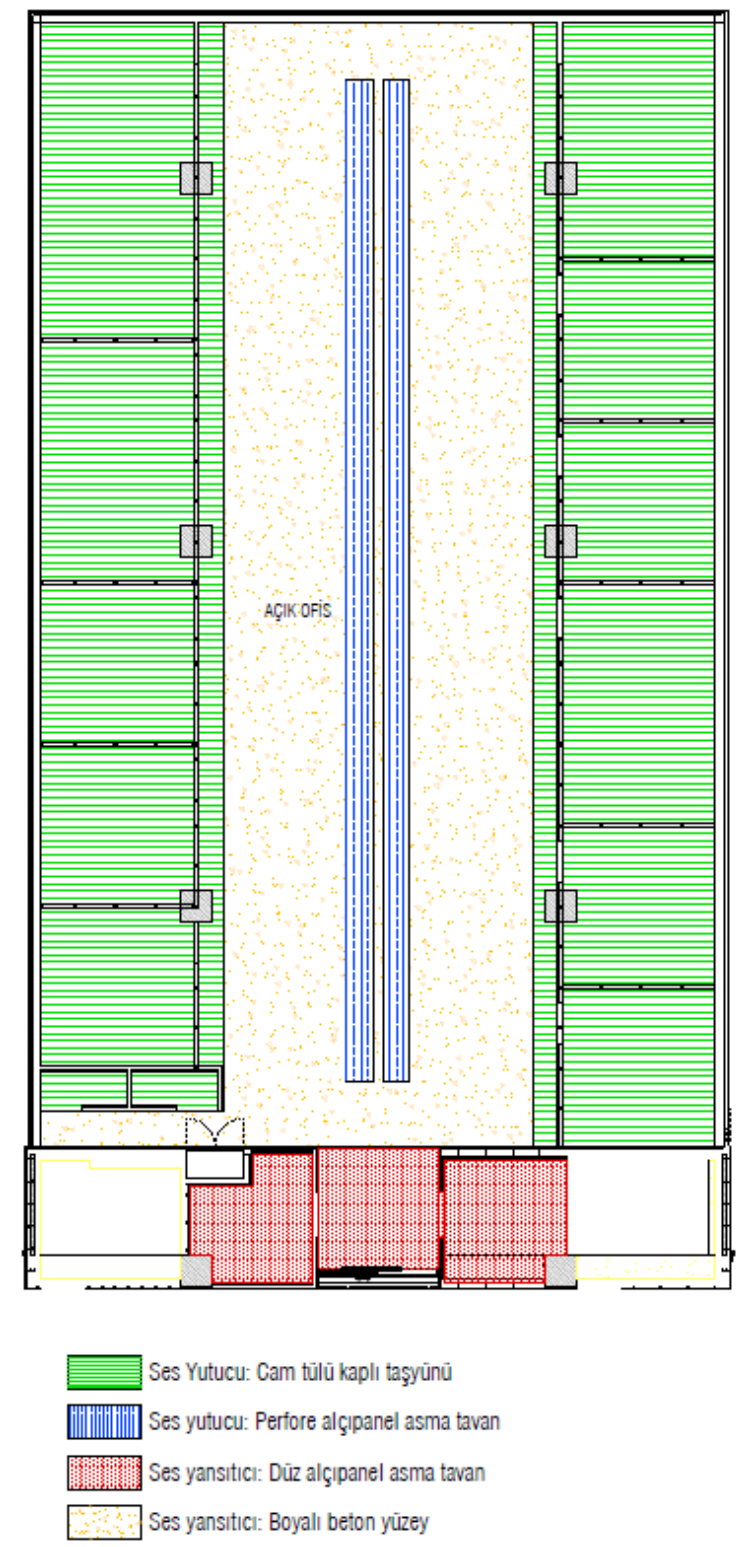

Şekil 2. Açık planlı ofis-1 planı

\section{Açık planlı ofis-1 için kaynak ve alıcı noktaları:}

Mobilyanın akustik üzerinde önemli bir etkisi olduğu için hesaplamalar mobilyalı ofislerde yapılmıştır. Kaynak ve alıcı konumları, zeminden 1,2 m yüksekliktedir. Hesaplamalar, iki kaynak konumundan eşit mesafelerde ve bir hat boyunca konumlandırılmış 7 alıcı noktasına kadar yapılmıştır.

Analizlerin gerçekleştirildiği hacimlerde, çalışma masaları arası bölmeler için $125 \mathrm{~cm}, 150 \mathrm{~cm}$ ve 175 cm yükseklik değerlendirmeleri yukarıda geçen parametreler üzerinden incelenmiştir. Bunlara ek olarak, çalışma birimleri arasında engel kullanılmadığı durumda da analizler gerçekleştirilmiştir. 


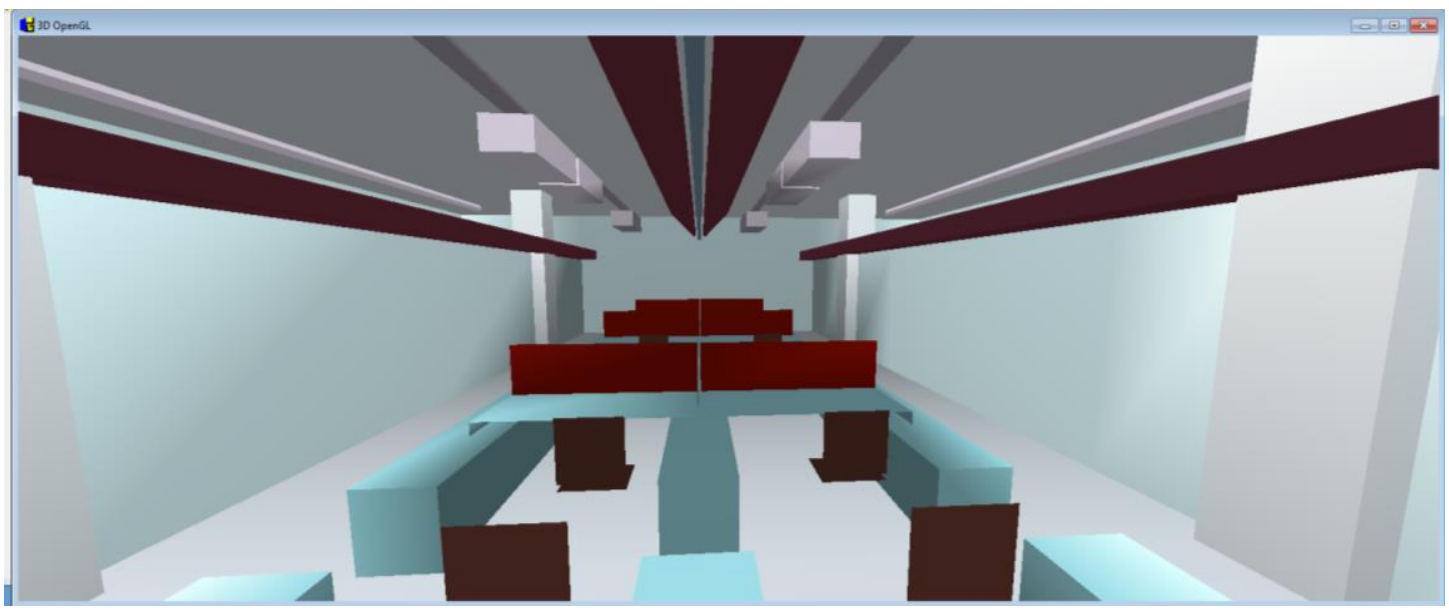

Şekil 3. Açık planlı ofis-1 odeon simülasyon programından iç görünüş

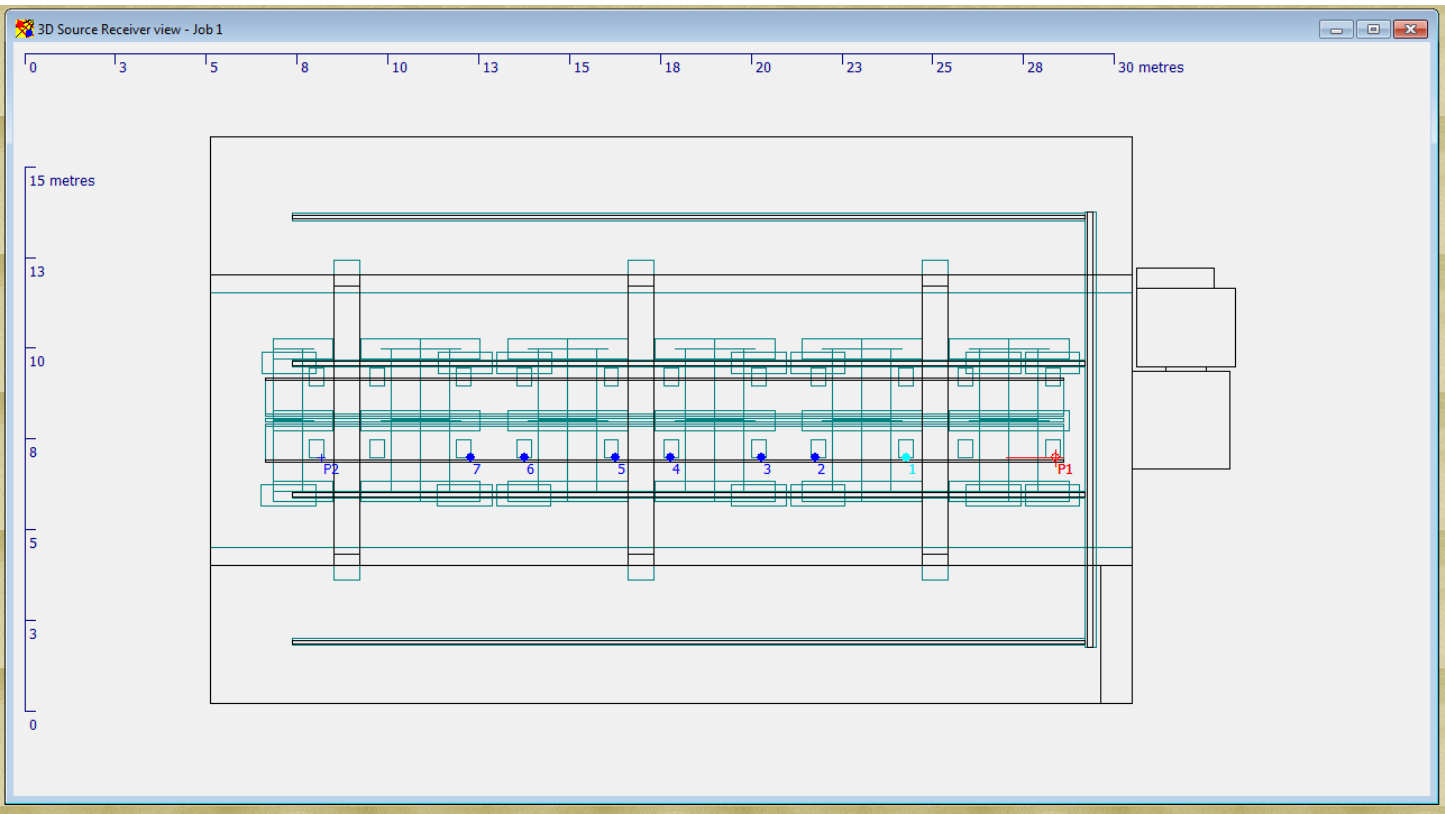

Şekil 4. Açık planlı ofis-1 - kaynak ve alıcı konumları-plan

Açık planlı ofis-1 için performans kriterlerinin değerlendirilmesi: 
Tablo 2. Açık planlı ofis-1 için performans kriterlerinin engel yüksekliğine göre analizi

\begin{tabular}{|c|c|c|c|c|c|c|c|c|}
\hline \multirow{2}{*}{$\begin{array}{l}\text { Engel yüksekliği } \\
\text { Kaynak konumuna göre hat } \\
\text { düzlemi }\end{array}$} & \multicolumn{2}{|c|}{ Engel Yok } & \multicolumn{2}{|c|}{$125 \mathrm{~cm}$} & \multicolumn{2}{|c|}{$150 \mathrm{~cm}$} & \multicolumn{2}{|c|}{$175 \mathrm{~cm}$} \\
\hline & Hat 1 & Hat 2 & Hat 1 & Hat 2 & Hat 1 & Hat 2 & Hat 1 & Hat 2 \\
\hline $\begin{array}{l}\text { En yakın çalışma birimindeki STI } \\
\text { değeri (STI in the nearest } \\
\text { Workstation) }\end{array}$ & 0,44 & 0,43 & 0,46 & 0,44 & 0,41 & 0,37 & 0,41 & 0,36 \\
\hline $\begin{array}{l}\text { Dikkat dağınıklığının azalmaya } \\
\text { başladığı uzaklık (rD) (STI daki } \\
\text { mekânsal azalma) (Distraction } \\
\text { distance, } \mathrm{r}_{\mathrm{D}} \text {, in m) }\end{array}$ & 0,19 & 0,95 & 0,98 & 1,39 & $*, * *$ & $*, * *$ & $*, * *$ & $*, * *$ \\
\hline $\begin{array}{l}\text { Gizliliğin başladığı uzaklık (re ) } \\
\text { (STI daki mekânsal azalma) } \\
\text { (Privacy distance, } \mathrm{r}_{\mathrm{P}} \text {, in m) }\end{array}$ & 15,86 & 15,40 & 15,04 & 14,62 & 12,25 & 12,54 & 11,21 & 11,59 \\
\hline $\begin{array}{l}\text { Konuşma sesinin A-ağırlıklı ses } \\
\text { basınç düzeyinin azalma oranı } \\
\text { (D2,S) (mekânsal sönümlenme } \\
\text { miktarı) (Spatial decay rate of A- } \\
\text { weighted SPL of speech, D2,S, in } \\
\text { dB) }\end{array}$ & 4,01 & 4,13 & 4,98 & 4,42 & 4,98 & 4,77 & 5,93 & 5,37 \\
\hline $\begin{array}{l}\text { 4m uzaklıktaki konuşma sesinin A } \\
\text { ağırlıklı ses basınç düzeyi } \\
\text { (Lp,A,S,4 m) (A-weighted SPL of } \\
\text { speech at } 4 \text { metres, Lp,A,S,4 m, in } \\
\text { dB) }\end{array}$ & 51,58 & 51,75 & 52,02 & 51,38 & 49,71 & 49,88 & 49,62 & 49,42 \\
\hline $\begin{array}{l}\text { Arka plan gürültü düzeyi (Lp,A,B) } \\
\text { (Average A-weighted background } \\
\text { noise, Lp,A,B, in } d B \text { ) }\end{array}$ & 43,77 & 43,77 & 43,77 & 43,77 & 43,77 & 43,77 & 43,77 & 43,77 \\
\hline
\end{tabular}

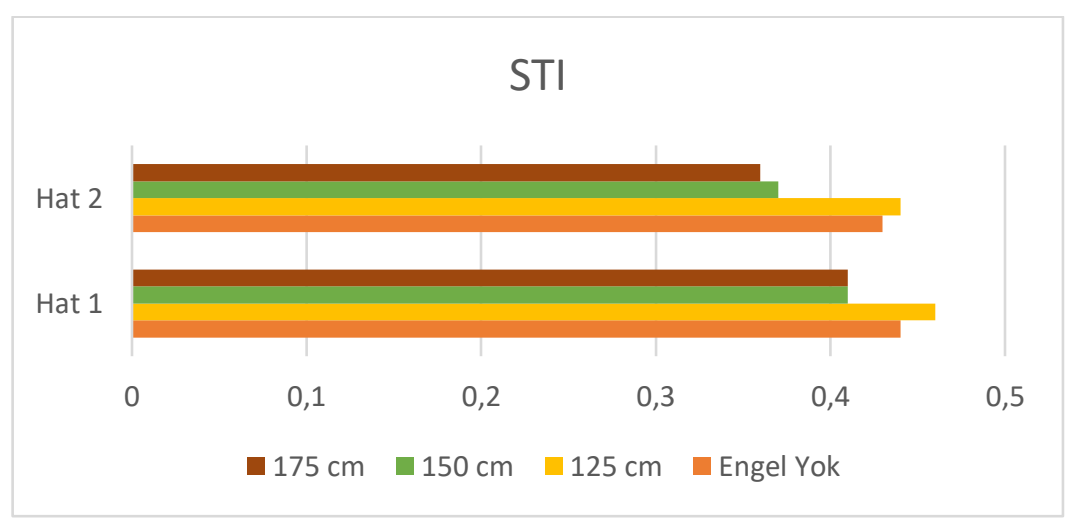

Şekil 9. Açık planlı ofis-1 için STI grafiği

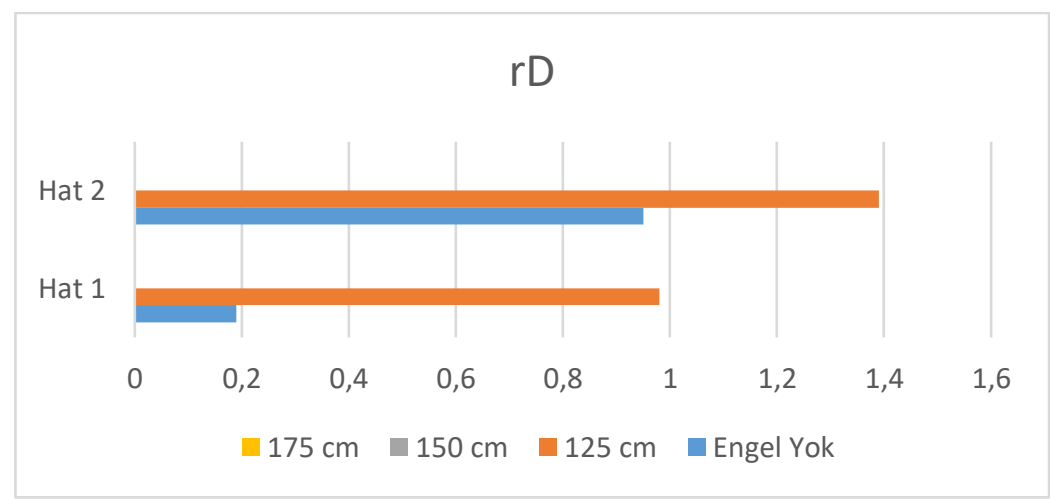

Şekil 10. Açık planlı ofis-1 için rD grafiği 


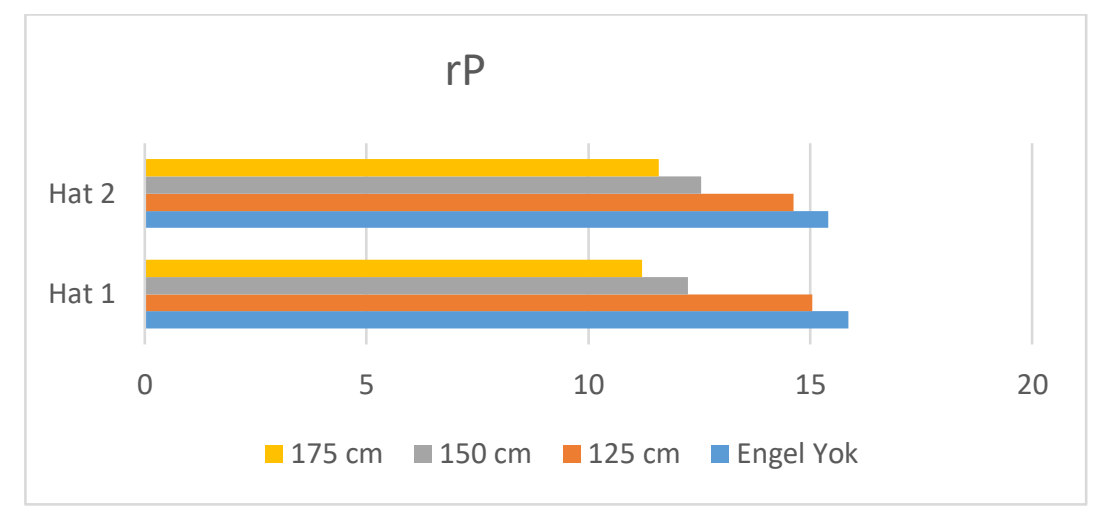

Şekil 11. Açık planlı ofis-1 için rP grafiği

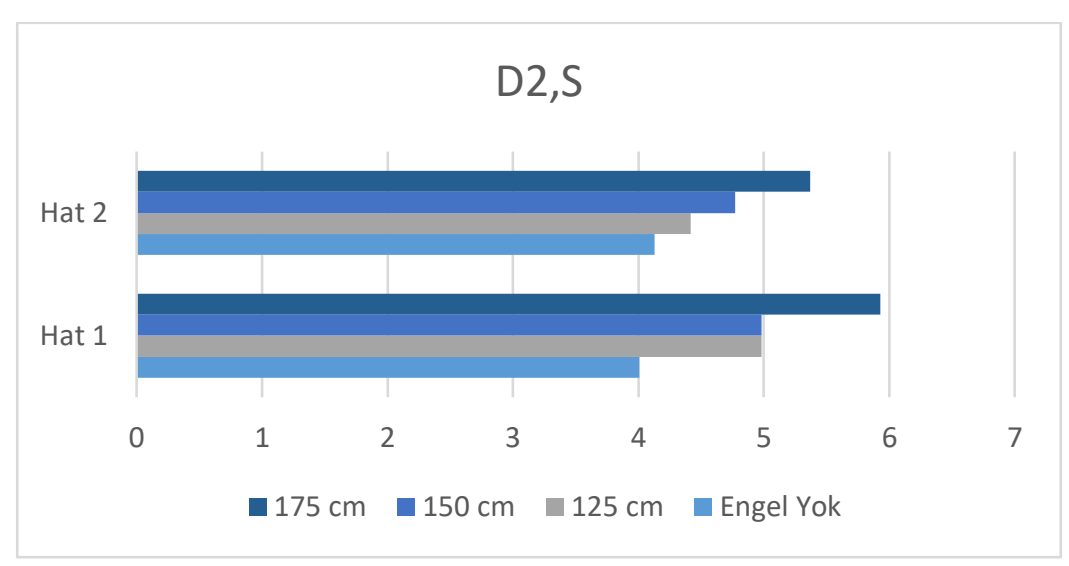

Şekil 12. Açık planlı ofis-1 için $\mathrm{D}_{2, \mathrm{~S}}$ grafiği

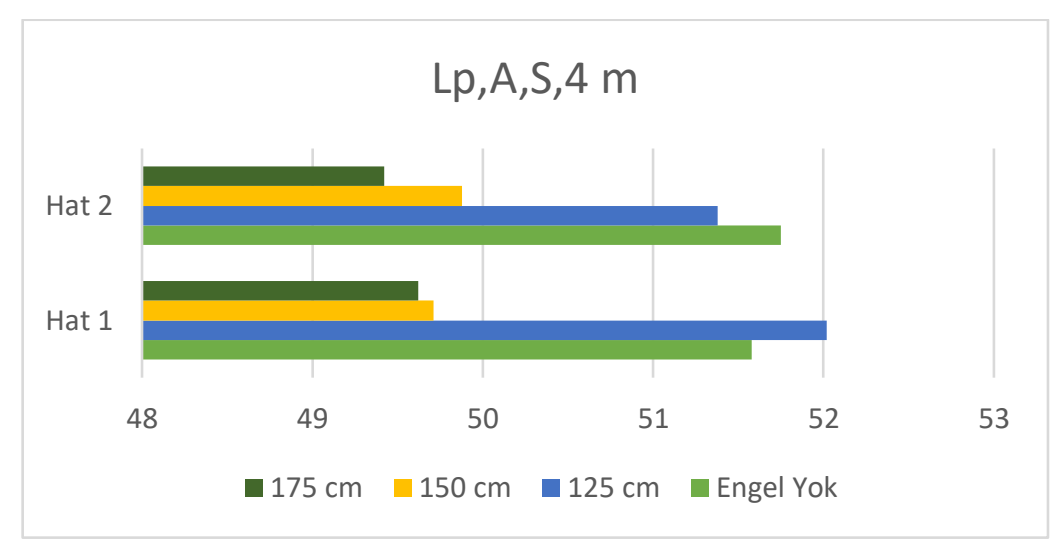

Şekil 13. Açık planlı ofis-1 için $\mathrm{L}_{\mathrm{p}, \mathrm{A}, \mathrm{S}, 4 \mathrm{~m}}$ grafiği 


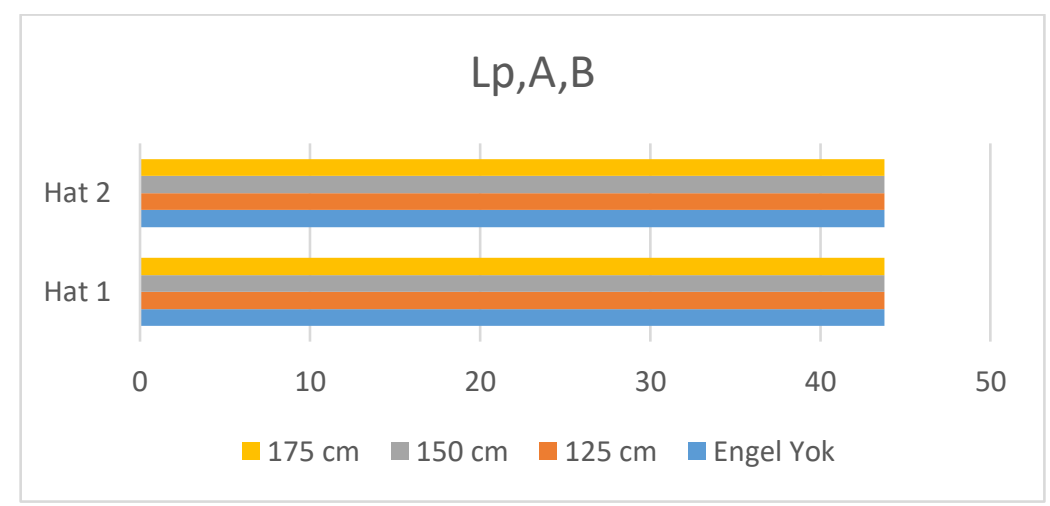

Şekil 14. Açık planlı ofis-1 için $\mathrm{L}_{\mathrm{p}, \mathrm{A}, \mathrm{B}}$ grafiğgi

\subsubsection{Açık planlı ofis-2 değerlendirilmesi:}

Açık planlı ofis-2 değerlendirilmesinde;

Tavan için;

- Perfore alçı panel asma tavan (taş yünü dolgulu)

- Cam tülü kaplı taş yünü kullanımı önerilmiştir.

- Masalar arası bölmeler için;

- Kumaş kaplı akustik panel kullanımı önerilmiştir (Şekil 15, Şekil 16)

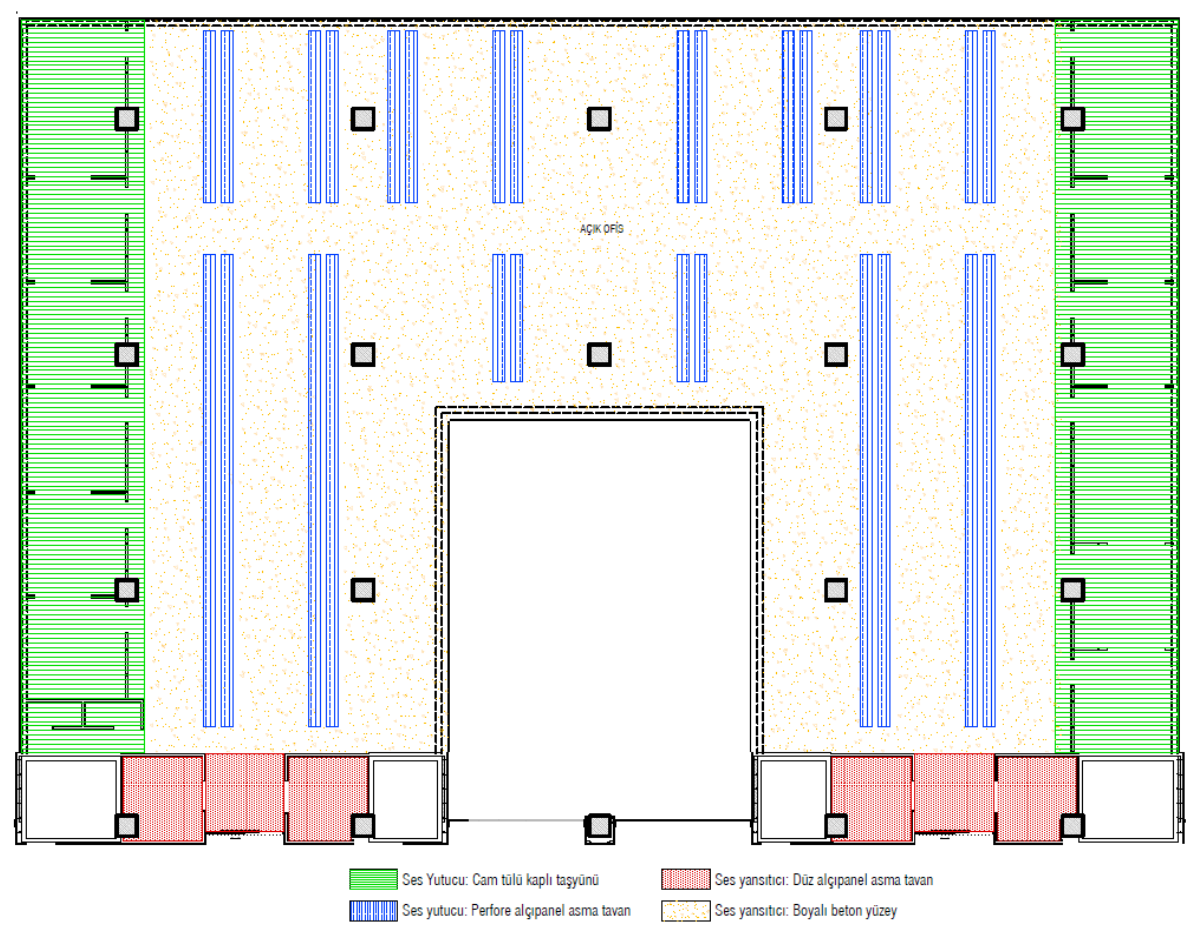

Şekil 15. Açık planlı ofis-2 planı 


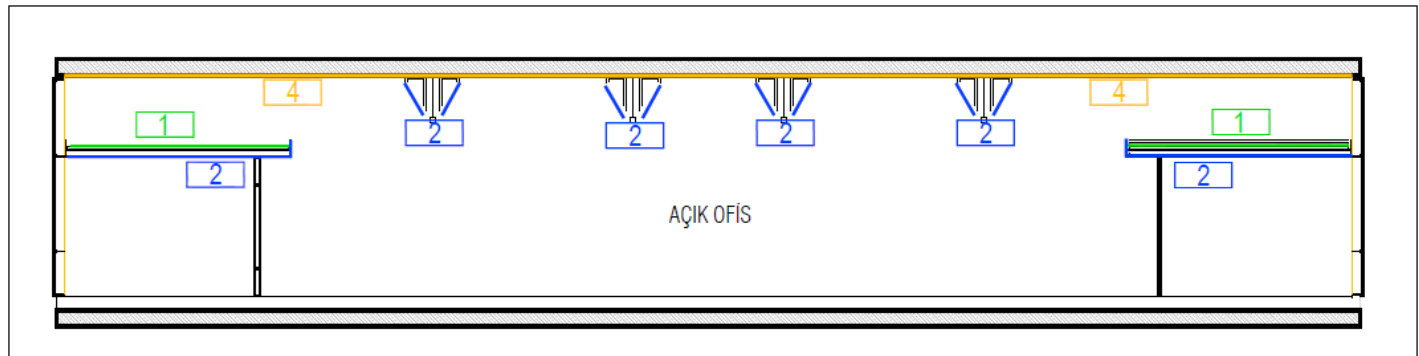

Ses Yutucu: Cam tülü kaplı taşyūnū

2 Ses yutucu: Perfore alçıpanel asma tavan

Ses yansiticl: Boyalı beton yüzey

Şekil 16. Açık planlı ofis-2 kesiti

Açık planlı ofis-2 için kaynak ve alıcı noktaları:

Mobilyanın akustik üzerinde önemli bir etkisi olduğu için hesaplamalar mobilyalı ofislerde yapılmıştır. Kaynak ve alıcı konumları, zeminden 1,2 m yüksekliktedir. Hesaplamalar, her iki kolda iki kaynak konumundan eşit mesafelerde ve bir hat boyunca konumlandırılmış 7 alıcı noktasına kadar yapılmıştır. Toplamda 4 kaynak konumu ve 14 alıcı noktası için analizler gerçekleştirilmiştir.

Analizlerin gerçekleştirildiği hacimlerde, çalışma masaları arası bölmeler için $125 \mathrm{~cm}, 150 \mathrm{~cm}$ ve 175 cm yükseklik değerlendirmeleri yukarıda geçen parametreler üzerinden incelenmiştir. Bunlara ek olarak, çalışma birimleri arasında engel kullanılmadığı durumda da analizler gerçekleştirilmiştir.

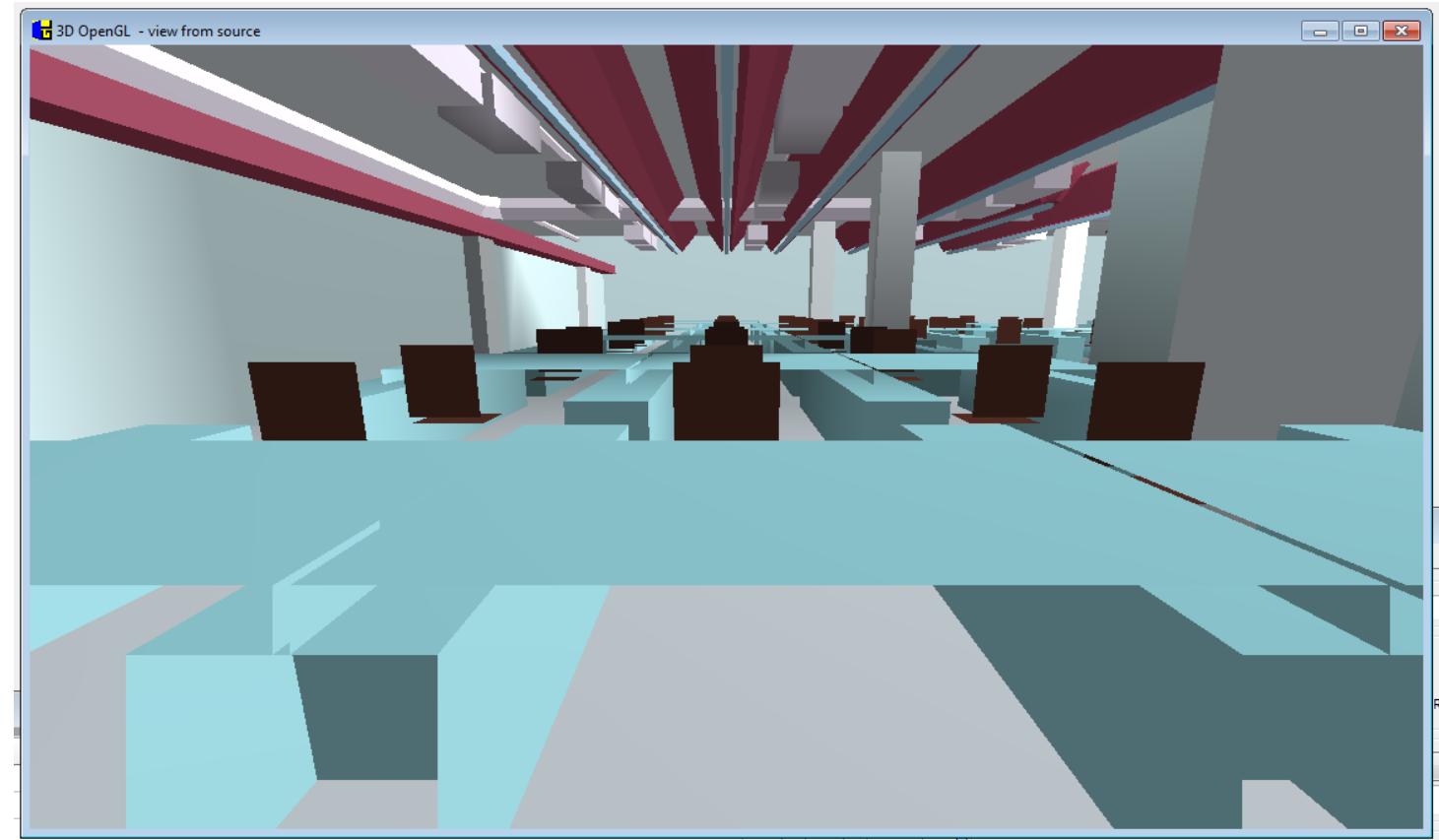

Şekil 17. Açık planlı ofis-2 odeon simülasyon programından iç görünüş 


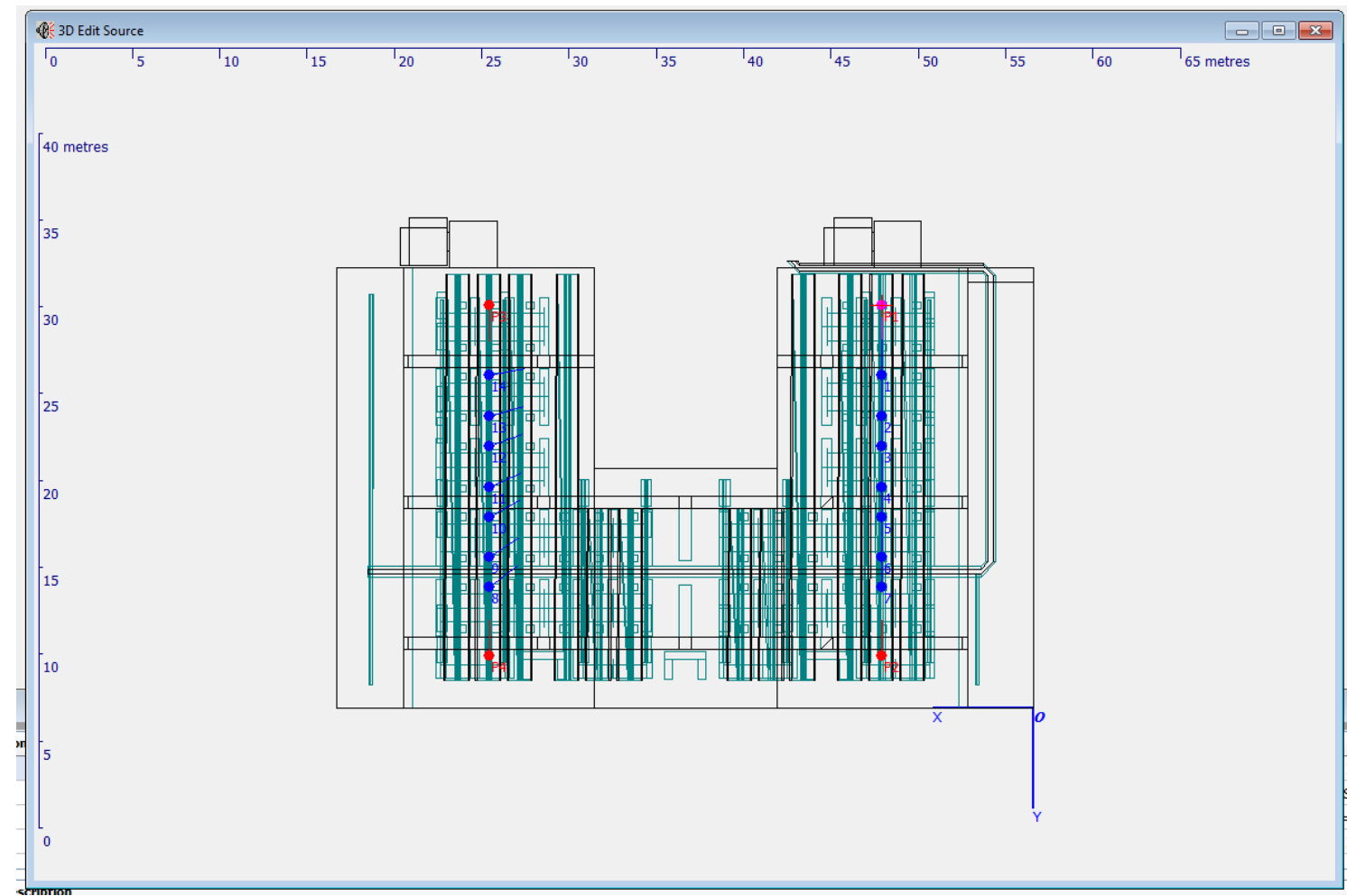

Şekil 18. Açık planlı ofis-2 - kaynak ve alıcı konumları-plan

Açık planlı ofis-2 için performans kriterlerinin dĕgerlendirilmesi:

Tablo 3. Açık planlı ofis-2 için performans kriterlerinin engel yüksekliğine göre analizi

\begin{tabular}{|c|c|c|c|c|c|c|c|c|}
\hline Engel yüksekliği & \multicolumn{4}{|c|}{ Engel Yok } & \multicolumn{4}{|c|}{$125 \mathrm{~cm}$} \\
\hline $\begin{array}{l}\text { Kaynak konumuna göre hat } \\
\text { düzlemi }\end{array}$ & Hat 1 & Hat 2 & Hat 3 & Hat 4 & Hat 1 & Hat 2 & Hat 3 & Hat 4 \\
\hline $\begin{array}{l}\text { En yakın çalışma birimindeki STI } \\
\text { değeri (STI in the nearest } \\
\text { Workstation) }\end{array}$ & 0,54 & 0,54 & 0,54 & 0,53 & 0,49 & 0,49 & 0,50 & 0,49 \\
\hline $\begin{array}{l}\text { Dikkat dağınıklığının azalmaya } \\
\text { başladığı uzaklık (rD) (STI daki } \\
\text { mekânsal azalma) (Distraction } \\
\text { distance, } \mathrm{r}_{\mathrm{D}}, \text { in } \mathrm{m} \text { ) }\end{array}$ & 4,72 & 3,34 & 4,60 & 4,07 & 0,95 & 0,63 & 0,95 & 2,20 \\
\hline $\begin{array}{l}\text { Gizliliğin başladığı uzaklık (rP ) (STI } \\
\text { daki mekânsal azalma) (Privacy } \\
\text { distance, } \mathrm{r}_{\mathrm{P}}, \text { in } \mathrm{m} \text { ) }\end{array}$ & 17,77 & 19,17 & 17,55 & 19,40 & 15,55 & 15,97 & 15,54 & 16,67 \\
\hline $\begin{array}{l}\text { Konuşma sesinin A-ağırlıklı ses } \\
\text { basınç düzeyinin azalma oranı }(\mathrm{D} 2, \mathrm{~S}) \\
\text { (mekânsal sönümlenme miktarı) } \\
\text { (Spatial decay rate of A-weighted } \\
\text { SPL of speech, D2,S, in dB) }\end{array}$ & 4,68 & 5,02 & 4,80 & 5,09 & 4,79 & 5,75 & 5,04 & 5,35 \\
\hline $\begin{array}{l}\text { 4m uzaklıktaki konuşma sesinin A } \\
\text { ağırlıklı ses basınç düzeyi (Lp,A,S,4 } \\
\text { m) (A-weighted SPL of speech at } 4 \\
\text { metres, Lp,A,S,4 m, in dB) }\end{array}$ & 50,00 & 49,34 & 50,15 & 49,81 & 46,75 & 46,89 & 47,17 & 47,42 \\
\hline $\begin{array}{l}\text { Arka plan gürültü düzeyi (Lp,A,B) } \\
\text { (Average A-weighted background } \\
\text { noise, Lp,A,B, in } d B \text { ) }\end{array}$ & 39,14 & 39,14 & 39,14 & 39,14 & 39,14 & 39,14 & 39,14 & 39,14 \\
\hline
\end{tabular}


Tablo 3. (Devamı) Açık planlı ofis-2 için performans kriterlerinin engel yüksekliğine göre analizi

\begin{tabular}{|c|c|c|c|c|c|c|c|c|}
\hline Engel yüksekliği & \multicolumn{4}{|c|}{$150 \mathrm{~cm}$} & \multicolumn{4}{|c|}{$175 \mathrm{~cm}$} \\
\hline $\begin{array}{l}\text { Kaynak konumuna göre hat } \\
\text { düzlemi }\end{array}$ & Hat 1 & Hat 2 & Hat 3 & Hat 4 & Hat 1 & Hat 2 & Hat 3 & Hat 4 \\
\hline $\begin{array}{l}\text { En yakın çalışma birimindeki STI } \\
\text { değeri (STI in the nearest } \\
\text { Workstation) }\end{array}$ & 0,50 & 0,49 & 0,51 & 0,48 & 0,49 & 0,48 & 0,50 & 0,47 \\
\hline $\begin{array}{l}\text { Dikkat dağınıklığının azalmaya } \\
\text { başladığı uzaklık (rD) (STI daki } \\
\text { mekânsal azalma) (Distraction } \\
\text { distance, } \mathrm{r}_{\mathrm{D}} \text {, in } \mathrm{m} \text { ) }\end{array}$ & $*, * *$ & $*, * *$ & $*, * *$ & $*, * *$ & $*, * *$ & $*, * *$ & $*, * *$ & $*, * *$ \\
\hline $\begin{array}{l}\text { Gizliliğin başladığı uzaklık (rP ) (STI } \\
\text { daki mekânsal azalma) (Privacy } \\
\text { distance, } \mathrm{r}_{\mathrm{P}}, \text { in } \mathrm{m} \text { ) }\end{array}$ & 13,86 & 13,77 & 13,61 & 14,53 & 11,35 & 12,34 & 11,51 & 13,57 \\
\hline $\begin{array}{l}\text { Konuşma sesinin A-ağırlıklı ses } \\
\text { basıç düzeyinin azalma oranı (D2,S) } \\
\text { (mekânsal sönümlenme miktarı) } \\
\text { (Spatial decay rate of A-weighted } \\
\text { SPL of speech, D2,S, in dB) }\end{array}$ & 8,57 & 6,82 & 8,75 & 6,84 & 10,93 & 8,14 & 9,71 & 7,42 \\
\hline $\begin{array}{l}\text { 4m uzaklıktaki konuşma sesinin A } \\
\text { ağırlıklı ses basınç düzeyi (Lp,A,S,4 } \\
\text { m) (A-weighted SPL of speech at } 4 \\
\text { metres, Lp,A,S, } 4 \mathrm{~m} \text {, in dB) }\end{array}$ & 48,19 & 45,72 & 48,27 & 46,60 & 47,94 & 46,25 & 47,08 & 45,89 \\
\hline $\begin{array}{l}\text { Arka plan gürültü düzeyi (Lp,A,B) } \\
\text { (Average A-weighted background } \\
\text { noise, Lp,A,B, in } d B \text { ) }\end{array}$ & 39,14 & 39,14 & 39,14 & 39,14 & 39,14 & 39,14 & 39,14 & 39,14 \\
\hline
\end{tabular}

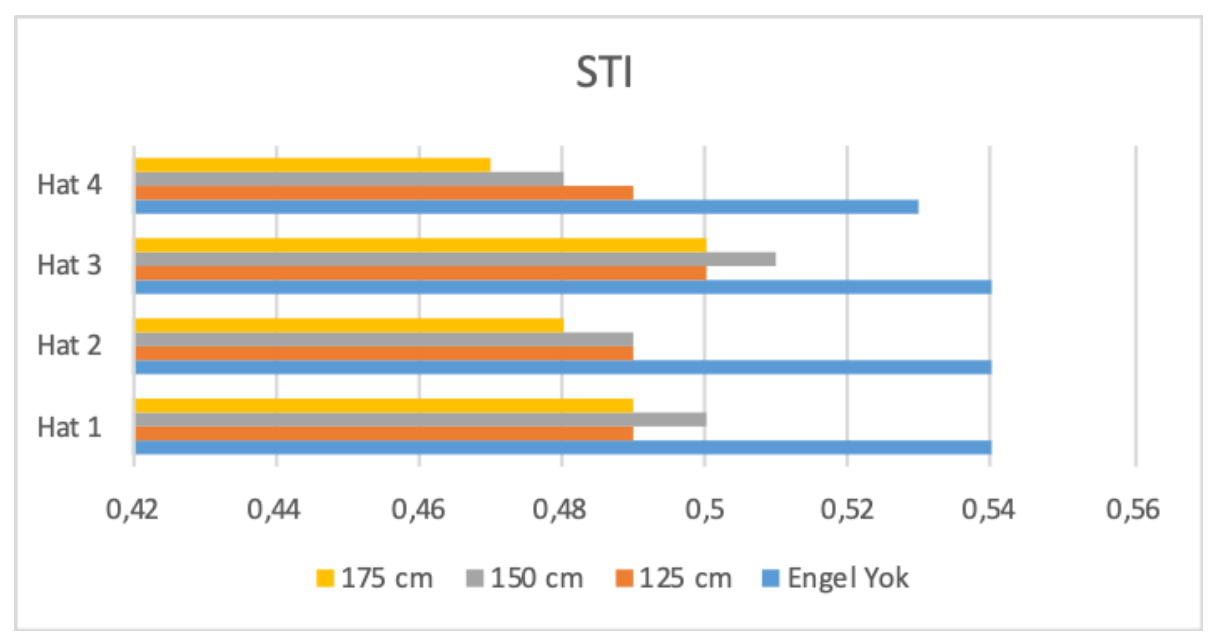

Şekil 19. Açık planlı ofis-2 için STI grafiğgi 
International Journal of Scientific and Technological Research

ISSN 2422-8702 (Online), DOI: 10.7176/JSTR/6-04-10

Vol.6, No.4, 2020

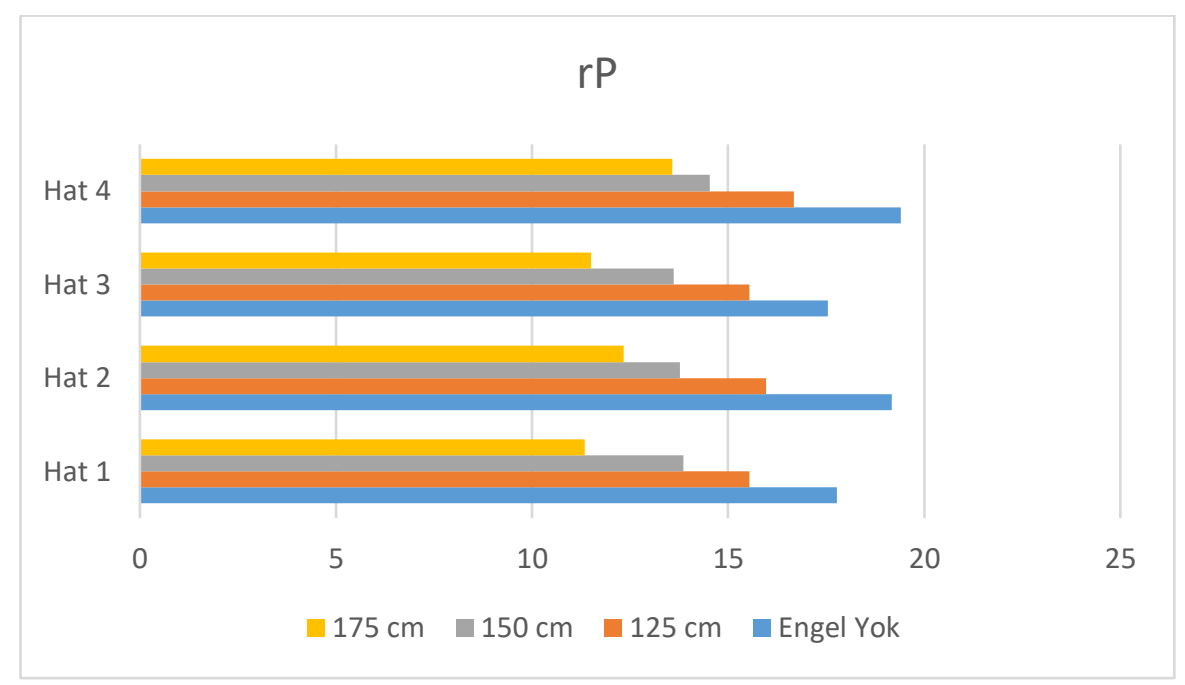

Şekil 20. Açık planlı ofis-2 için rP grafiği

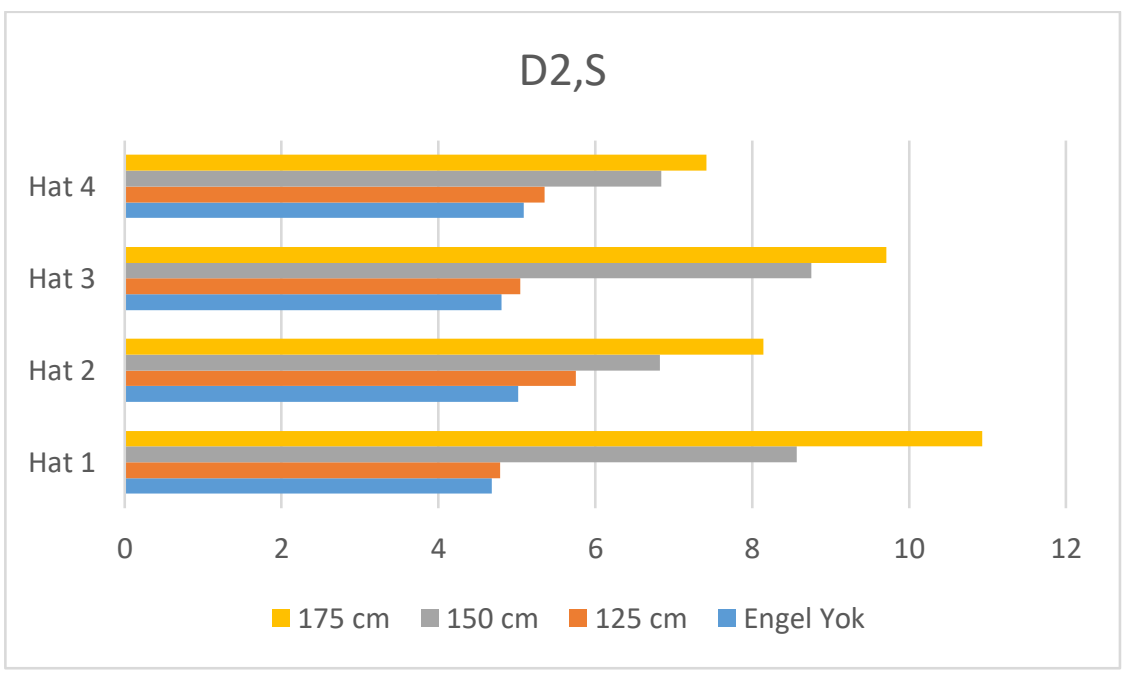

Şekil 21. Açık planlı ofis-2 için D2,S grafiği

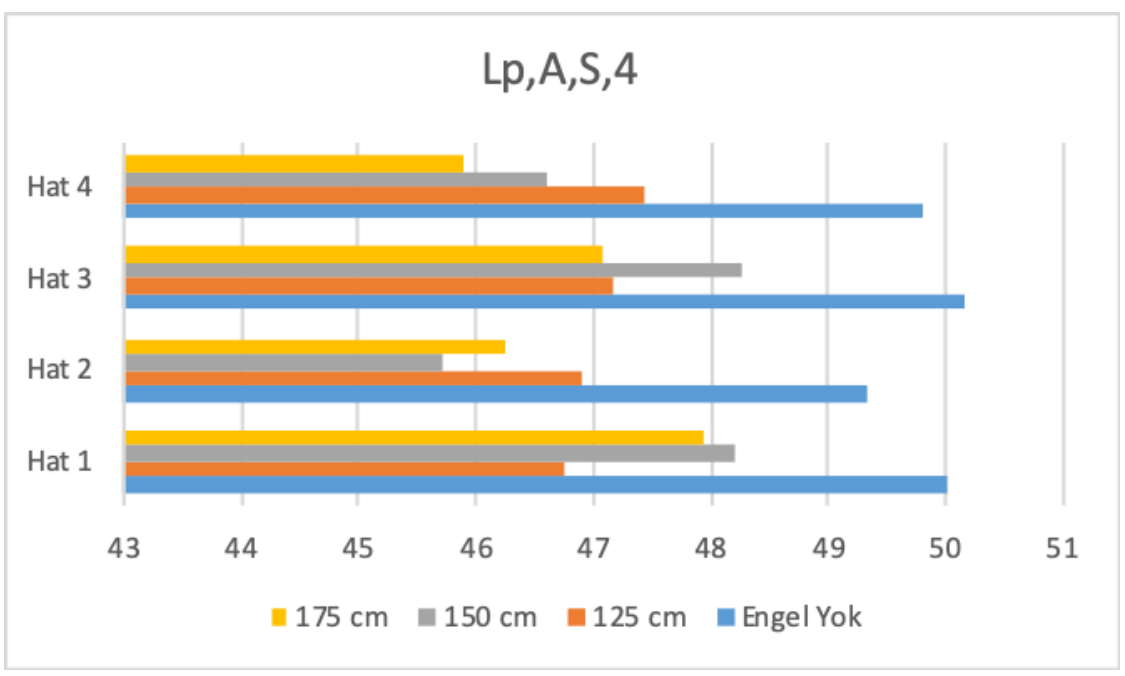

Şekil 22. Açık planlı ofis-2 için Lp,A,S,4 m grafiği 


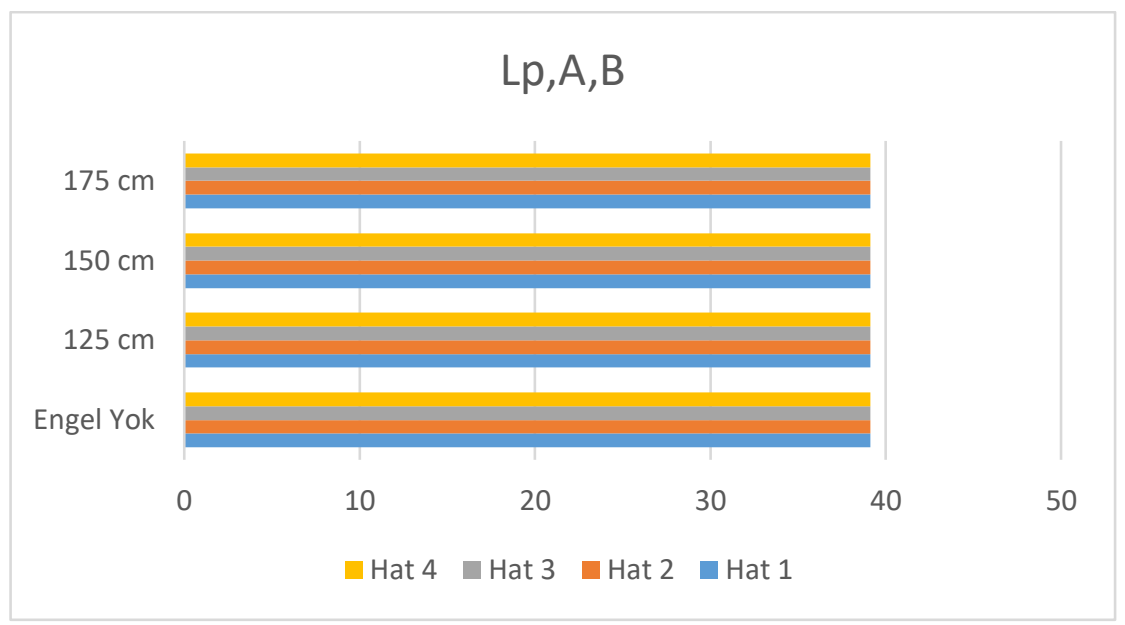

Şekil 23. Açık planlı ofis-2 için Lp,A,B grafiği

\section{SONUCC VE DEĞERLENDİRME}

ISO 3382-3 standardında hacim akustiği parametreleri, ortamın yutma karakteristiği, engel kullanımı ya da arka plan gürültüsü değiştiğinde farklılaşır. Parametreleri tek başına değerlendirmek doğru olmasa da akustik koşulların değerlendirmesi için bir parametre kombinasyonu gereklidir.

Örneğin, yalnızca dikkat dağınıklığının azalmaya başladığı mesafeye bakıldığında, reverberasyonun fazla olmasının iyi olduğu sonucuna varılabilir; ancak bu durum çok gürültülü koşullara yol açacaktır. Öte yandan, yalnızca A-ağırlıklı ses basınç düzeyinin azalma oranı bakıldığında, reverberasyon süresinin mümkün olduğu kadar kısa olması gerektiği sonucuna varılabilir; ancak bu, uzaktaki kaynaklar için bile çok yüksek anlaşılabilirliğe ve dolayısıyla çalışma sırasında dikkat dağınıklığı riskinin daha yüksek olmasına yol açabilir.

Açık planlı ofis-1'de;

\begin{tabular}{|c|c|c|c|c|}
\hline Engel yüksekliği & Engel Yok & $125 \mathrm{~cm}$ & $150 \mathrm{~cm}$ & $175 \mathrm{~cm}$ \\
\hline Kaynak konumuna göre hat düzlemi & \multicolumn{4}{|c|}{ ORT } \\
\hline $\begin{array}{l}\text { En yakın çalışma birimindeki STI değeri (STI in } \\
\text { the nearest Workstation) }\end{array}$ & 0,44 & 0,45 & 0,39 & 0,39 \\
\hline $\begin{array}{l}\text { Dikkat dağınıklığının azalmaya başladığı uzaklık } \\
\left(\mathrm{r}_{\mathrm{D}}\right)(\mathrm{STI} \text { daki mekânsal azalma) (Distraction } \\
\text { distance, } \mathrm{r}_{\mathrm{D}}, \text { in } \mathrm{m} \text { ) }\end{array}$ & 0,57 & 1,19 & $*$ & $*$ \\
\hline $\begin{array}{l}\text { Gizliliğin başladı̆̆ } 1 \text { uzaklık ( } \mathrm{r}_{\mathrm{P}} \text { ) (STI daki } \\
\text { mekânsal azalma) (Privacy distance, } \mathrm{r}_{\mathrm{P}} \text {, in m) }\end{array}$ & 15,63 & 14,83 & 12,40 & 11,40 \\
\hline $\begin{array}{l}\text { Konuşma sesinin A-ağılıklı ses basınç düzeyinin } \\
\text { azalma oranı (D2,S) (mekânsal sönümlenme } \\
\text { miktarı) (Spatial decay rate of A-weighted SPL of } \\
\text { speech, D2,S, in dB) }\end{array}$ & 4,07 & 4,70 & 4,88 & 5,65 \\
\hline $\begin{array}{l}4 \mathrm{~m} \text { uzaklıktaki konuşma sesinin A ağırlıklı ses } \\
\text { basıç düzeyi (Lp,A,S, } 4 \mathrm{~m} \text { ) (A-weighted SPL of } \\
\text { speech at } 4 \text { metres, Lp,A,S,4 m, in dB) }\end{array}$ & 51,67 & 51,70 & 49,80 & 49,52 \\
\hline $\begin{array}{l}\text { Arka plan gürülttü düzeyi (Lp,A,B) (Average A- } \\
\text { weighted background noise, } L p, A, B \text {, in } \mathrm{BB} \text { ) }\end{array}$ & 43,77 & 43,77 & 43,77 & 43,77 \\
\hline
\end{tabular}

STI değeri optimum değerlerin altındadır. Ofis içerisindeki çalışanların mahremiyetlerinin yeterli ölçüde sağlandığı ve söz konusu ofiste akustik konforun yeterli olduğu sonucuna varılmıştır. 
Dikkat dağınıklığının azalmaya başladığı uzaklıkla ilgili olarak; rD $\leq 5 \mathrm{~m}$ olduğu için iyi bir ofistir yorumu yapılabilir.

Konuşma sesinin A-ağırlıklı ses basınç düzeyinin azalma oranı $\left(\mathrm{D}_{2, \mathrm{~S}}\right)$ parametresinin $175 \mathrm{~cm}$ engel haricinde diğer mesafelerde optimum değeri sağlamadığ

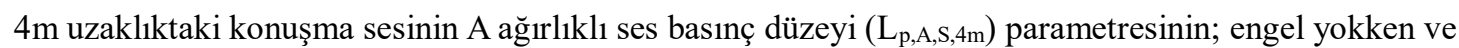
$125 \mathrm{~cm}$ engel varken kötü bir ofis durumunda olduğu, $150 \mathrm{~cm}$ ve $175 \mathrm{~cm}$ engel yüksekliklerinde sinır değerlere yaklaştığ

Açık planlı ofis-2'de;

\begin{tabular}{|c|c|c|c|c|}
\hline Engel yüksekliği & Engel Yok & $125 \mathrm{~cm}$ & $150 \mathrm{~cm}$ & $175 \mathrm{~cm}$ \\
\hline Kaynak konumuna göre hat düzlemi & \multicolumn{4}{|c|}{ ORT } \\
\hline $\begin{array}{l}\text { En yakın çalışma birimindeki STI değeri (STI in the } \\
\text { nearest Workstation) }\end{array}$ & $\mathbf{0 , 5 4}$ & $\mathbf{0 , 4 9}$ & $\mathbf{0 , 5 0}$ & $\mathbf{0 , 4 9}$ \\
\hline $\begin{array}{l}\text { Dikkat dağınıklığının azalmaya başladığı uzaklık }\left(\mathrm{r}_{\mathrm{D}}\right) \\
\text { (STI daki mekânsal azalma) (Distraction distance, } \mathrm{r}_{\mathrm{D}} \text {, in } \\
\mathrm{m} \text { ) }\end{array}$ & 4,18 & 1,18 & 13,94 & 12,19 \\
\hline $\begin{array}{l}\text { Gizliliğin başladığ }{ }_{1} \text { uzaklık ( } \mathrm{r}_{\mathrm{P}} \text { ) (STI daki mekânsal } \\
\text { azalma) (Privacy distance, } \mathrm{r}_{\mathrm{P}} \text {, in m) }\end{array}$ & 18,47 & 15,93 & $\mathbf{7 , 7 5}$ & $\mathbf{9 , 0 5}$ \\
\hline $\begin{array}{l}\text { Konuşma sesinin A-ağırliklı ses basınç düzeyinin azalma } \\
\text { oranı (D2,S) (mekânsal sönümlenme miktarı) (Spatial } \\
\text { decay rate of A-weighted SPL of speech, D2,S, in dB) }\end{array}$ & 4,90 & 5,23 & 47,20 & 46,79 \\
\hline $\begin{array}{l}\text { 4m uzaklıktaki konuşma sesinin A ağırlıklı ses basınç } \\
\text { düzeyi (Lp,A,S,4 m) (A-weighted SPL of speech at } 4 \\
\text { metres, Lp,A,S,4 m, in dB) }\end{array}$ & 49,83 & 47,06 & 39,14 & 39,14 \\
\hline $\begin{array}{l}\text { Arka plan gürültü düzeyi (Lp,A,B) (Average A-weighted } \\
\text { background noise, Lp,A,B, in } \mathrm{BB})\end{array}$ & 39,14 & 39,14 & 13,94 & 12,19 \\
\hline
\end{tabular}

STI değeri, engel olmadığı durumda optimum değerlerin üstünde, $150 \mathrm{~cm}$ engel yüksekliğinde sınır değerde olduğu görülmektedir. Ofis içerisindeki çalışanların mahremiyetlerinin engel olmadığında yeterli ölçüde sağlanmadığı ve söz konusu ofiste akustik konforun yeterli olmadığı sonucuna varılmıştır. $125 \mathrm{~cm}$ ve $175 \mathrm{~cm}$ engel yüksekliğinde uygun değerlerde olduğu tespit edilmiştir.

Dikkat dağınıklığının azalmaya başladığı uzaklıkla ilgili olarak; rD $\leq 5$ m olduğu için; engel olmadığında ve $125 \mathrm{~cm}$ engel olduğu durumlarda iyi bir ofistir yorumu yapılabilir. $150 \mathrm{~cm}$ ve $175 \mathrm{~cm}$ yüksekliğinde ise STI değerleri $\mathrm{rD}>10 \mathrm{~m}$ ise olduğu için kötü bir ofistir denebilir.

Konuşma sesinin A-ağırlıklı ses basınç düzeyinin azalma oranı $\left(\mathrm{D}_{2, \mathrm{~s}}\right)$ parametresi; engel olmadığında ve $125 \mathrm{~cm}$ engel yüksekliği için kötü bir ofis, $150 \mathrm{~cm}$ ve $175 \mathrm{~cm}$ engelde; $\mathrm{D}_{2, \mathrm{~S}} \geq 7 \mathrm{~dB}$ iyi bir ofistir yorumu yapilabilir.

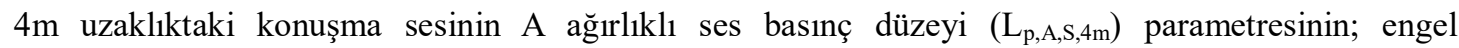
olmadığında, kötü bir ofis olarak belirlenirken, $125 \mathrm{~cm}, 150 \mathrm{~cm}$ ve 175 engel yüksekliklerinde Lp,A,S,4m $\leq 48 \mathrm{~dB}$ olduğu için uygun değerlerde olduğu söylenebilir.

Açık planlı bu ofislerde konuşmanın gizliliğinin sağlanabilmesi için TS EN ISO 3382-3 (2012) standardında bulunan tüm hacim akustiği parametrelerinin aldığı değerlerin uygun aralıklarda olması gerektiği öngörülmektedir. Ayrıca uluslararası alanda yapılan çalışmalar da bulunan sonucu doğrular nitelikte olup, tüm parametrelerin tek başına yeterli olmadığ sonucuna ulaşılmaktadır. Açık planlı ofislerde incelenen bu parametrelerin bütüncül olarak değerlendirilmesi, çalışanların konforunu ve iş gücü verimliliğini de arttıracağı düşünülmektedir. 


\section{TEŞEKKÜR}

Bu çalışma; Gazi Üniversitesi ve Siirt Üniversitesi Döner Sermayeleri aracılığı ile yapılmış olan projeden oluşturulmuştur.

\section{Kaynaklar}

[1] Çete, N., Çalışma Ortamlarında Verimliliğin Artırılmasının Büro Mekânlarıyla İlişkilendirilmesi, Yayınlanmamış Yüksek Lisans Tezi, İstanbul, Yıldız Teknik Üni., Fen Bilimleri Enstitüsü. (2004).

[2] Charles, K., Pero, K., Open Plan Office Designs-Promoting Organizational Productivity, Construction Canada, v.48, no.4, (2006).

[3] Karabiber, Z., Açık Planlı Bürolarda Akustik Sorunlar, Tasarım Dergisi, Sayı:49, s.103-105, (1994).

[4] NRCC, Workstation Design for Organizational Productivity, 2004.

[5] Kallaus, F.N \& Kelling, B., Administrative Office Management, Cincinati, pp.3, 1991.

[6] NRCC, Workstation Design for Organizational Productivity, pp.1, 2004.

[7] Charles, K., Pero, K., Open Plan Office Designs-Promoting Organizational Productivity, Construction Canada,v.48, no.4, 2006.

[8] Çevre ve Şehircilik Bakanlığı, Binaların Gürültüye Karşı Korunması Hakkında Yönetmelik, Resmi Gazete, Ankara, 31.05.2017.

[9] TS EN ISO 3382-3, Akustik - Oda akustik parametrelerinin ölçülmesi - Bölüm 3: Açık planlı ofisler, 2012.

[10] TS EN ISO 11690, Akustik - içinde makina bulunan düşük gürültü seviyeli iş yerlerinin tasarımı için tavsiye edilen uygulama - Bölüm 1: Gürültü kontrol stratejileri, 1999.

[11] Wenmaekers, R., Hak, C. (2015, 31 May-3 June). Spatial decay rate of speech in open plan offices: the use of D2,S and LP,A,S,4m as building requirements. EuroNoise 2015, Maastricht, Holland, 2015.

[12] Virjonen, P., Keranen J., and Hongisto, V., Determination of acoustical conditions in open-plan offices: Proposal for new measurement method and target values. Acta Acustica United With Acustica, 95, 279-290, 2009.

[13] Mehta, M., Johnson, J., and Rocafort, J., Architectural acoustics: Principles and design. New Jersey: Prentice Hall, 1999.

[14] Demirel, F., Görkem, M., Özçetin, Z., Açık Planlı Ofislerde Engel Etkinliğinin Araştırılması: Bir Örnek İnceleme, 13. Ulusal Akustik Kongresi ve Sergisi, Diyarbakır, 2019.

[15] Tunç, K.,T., Demirel, F., Kandemir, H., An Investigation Into The Acoustic Conditions Of An Open Plan Office Located In Ankara, Internoise, Hamburg, Germany, 2016.

[16] ODEON Material Library

[17] Odeon A/S, “Room Acoustics Modelling Software, V 15.04 Auditorium”, Denmark, (2019).

[18] Rindel, J.,H., Christensen. C, L. Acoustical simulation of open-plan offices according to ISO 3382-3, Euronoise, Prague, 2012. 
[19] Rindel, J.,H., Odeon application note - ISO 3382-3 Open plan offices, Odeon Room Acoustic Software, 2012.

[20] Rindel, J.,H., Odeon application note - ISO 3382-3 Open plan offices - Part 2 Measurements, Odeon Room Acoustic Software, 2014.

[21] Demirel, F., Mimari Akustik Yayınlanmamış Ders Notları, Gazi Üniversitesi Mimarlık Fakültesi, Ankara (2020). 